\title{
o pensamento industrialista na formação do Estado Nacional brasileiro. Análise de um escrito de João Severiano Maciel da Costa (1820)
}

\author{
Lupercio Antonio Pereira*
}

Neste artigo, analisamos o pensamento industrialista formulado por João Severiano Maciel da Costa em 1820. Numa Memória dedicada à escravidão e ao tráfico africano, Maciel da Costa acabou enveredando para uma discussão a respeito das estratégias de desenvolvimento da economia brasileira e, ao fazê-lo, distanciou-se da visão livre-cambista e defendeu o intervencionismo estatal e a proteção à indústria nacional. Por um lado, essa Memória mostra que o pensamento industrialista brasileiro nasceu antes da proclamação oficial da Independência. Por

\section{J oão Severiano Maciel da Costa} primeiros e mais importantes expoentes da escola protecionista no pensamento econômico brasileiro ${ }^{1}$. Ele integra aquele seleto grupo que desempenhou papel de relevo no mundo político e intelectual luso-brasileiro nas primeiras décadas do século XIX e, por essa

\footnotetext{
* Doutor em História Social pela USP. Prof. do Departamento de História e do Programa de PósGraduação em História. Universidade Estadual em Maringá/PR.lupantonio@uol.com.br

${ }^{1}$ Se formos investigar a origem intelectual mais remota do industrialismo brasileiro, vamos encontrá-la nos mercantilistas portugueses que, desde o século XVII, defendiam uma série de medidas protecionistas com vistas ao desenvolvimento manufatureiro de Portugal. Ver: SÉRGIO, Antonio - Antologia dos Economistas Portugueses (Séc. XVII). Lisboa, Sá da Costa, 1974, e Breve Interpretação da História de Portugal. Lisboa, [1929] 1983, NOVAIS, Fernando Antonio - Estrutura e dinâmica do Antigo Sistema Colonial. SP, Brasiliense, 1986, SERRÃO, Joel e MARTINS, Gabriela - Da Indústria Portuguesa. Do Antigo regime ao Capitalismo. Lisboa, Livros Horizonte, 1978, PEREIRA, Silvina Rosa - Escritório Avarento - Uma Apologia do Dinheiro. Assis, UNESP, Dissertação de Mestrado, 1984, MENEZES, Sezinando Luiz - Alexandre Gusmão (1695-1753): uma reiteração dos impasses da história portuguesa.SP, USP, 1998. (Tese de Doutorado)
} 
outro, a posição de destaque assumida pelo autor no processo de construção do Estado Imperial brasileiro mostra que o pensamento industrialista estava presente no núcleo duro do sistema de poder do Primeiro Reinado, o que põe em questão a tese de que o processo de independência teria sido conduzido por um grupo organizado em torno de um único pensamento econômico, o livre-cambismo.

Palavras-chave: Maciel da Costa; Industrialismo; Independência.

This article focuses the industrialist ideas of João Severiano Maciel da Costa in 1820. In his study about slavery and African traffic, Maciel da Costa eventually held discussions about the Brazilian economy development strategies and, in doing so, became distant from the free-trade vision and overtly defended the state interventionism and the national industry protection. On the one side, he shows that the Brazilian industrialist ideas were born before the official proclamation of Independence. On the other hand, the author's important position in the process of construction of the Brazilian Imperial State shows that the industrialist ideas were already present in the hardcore of the First Reign power system, which raises the thesis that the independence process would have been conducted by an organized group around a single economic thought namely the free-trade.

Key words: Maciel da Costa. Industrialism. Independence.

razão, acabou se transformando num dos protagonistas do processo que levaria à Independência do Brasil. Durante o período do Reino Unido do Brasil e Portugal, Maciel da Costa exerceu a importante função de governador da Guiana Francesa, ocupada por forças luso-brasileiras entre 1808 e 1817 como retaliação à ocupação de Portugal pelas tropas napoleônicas².

Nos momentos iniciais da Revolução Liberal do Porto, eclodida em 24 de agosto de 1820, João Maciel da Costa colocou-se como um dos articuladores do grupo que ainda apostava na fórmula do Reino Unido do Brasil, Portugal e Algarves. Com o desenrolar dos acontecimentos, porém, ele acabou apoiando o grupo que optou pela ruptura total com Portugal, embora, no ano da Independên-

\footnotetext{
${ }^{2}$ Há uma curiosidade interessante sobre a passagem de Maciel da Costa pela Guiana Francesa. Foi por iniciativa dele que plantas como o abacateiro, a fruta-pão, a palmeira real e a cana caiana (aportuguesamento de canne de Cayenne), cultivadas na Guiana, foram introduzidas no Brasil. (SOUTO MAIOR, A. - História do Brasil. São Paulo, Cia Editora Nacional, 1971. A essa lista de produtos transplantados da Guiana para o Brasil por iniciativa de Maciel da Costa, o seu biógrafo acrescenta a chamada árvore de carvão e mais as seguintes especiarias: cravo da índia, noz-moscada e canela. Esse biógrafo acrescenta ainda que, durante o período em que administrou aquela colônia francesa, Maciel da Costa chegou a elaborar um estudo para incorporação das Guianas Francesa e Holandesa aos domínios do rei de Portugal. (SOUZA, Miguel Gonçalves de - O Marquês de Queluz e sua Época,1988.)
} 
cia propriamente dito, não estivesse no Brasil, porque, por ordem das Cortes, ficara retido em Portugal.

Em 1821, juntamente com Felisberto Caldeira Brant, Maciel da Costa havia sido enviado por Dom João VI em missão político-diplomática na Europa. O pretexto da viagem era uma missão em Roma para Maciel da Costa e uma em Londres para Caldeira Brant, com escala em Portugal. Na verdade, tratava-se de uma missão de sondagem sobre a situação política de Portugal e sobre a verdadeira intenção dos constituintes, após estes terem dado a ordem de retorno a Dom João VI. Visto com suspeita pelas Cortes, Maciel da Costa ficou retido em Coimbra e só retornou ao Brasil em 1823, quando assumiu uma vaga de Deputado junto à Assembléia Constituinte, para a qual fora eleito ainda quando estava confinado em Portugal.

Teve atuação destacada na Assembléia Constituinte, chegando inclusive a ser eleito seu presidente no sistema de rodízio mensal adotado pelos deputados constituintes. Nessa eleição, realizada na sessão de 31 de outubro de 1823, Maciel da Costa derrotou nada menos que um dos poderosos irmãos Andrada, Martim Francisco. A dissolução da constituinte por Dom Pedro I ocorreu sob sua presidência ${ }^{3}$.

A posição de destaque de Maciel da Costa no processo de Independência e de formação do Estado Nacional brasileiro pode ser aferida também pelo fato de ele ter sido um dos signatários da Constituição do Império outorgada em 18244, o que significa dizer que o mesmo fazia parte do núcleo duro da estrutura de poder montada em torno do príncipe da Casa de Bragança. A assinatura de Maciel da Costa aparece duplamente na Carta Constitucional de 1824: na qualidade de presidente do Conselho de Estado que elaborou a Carta e como titular do Ministério do Império, órgão encarregado de sua publicação.

Outorgada a Constituição e regularizada a vida política do primeiro reinado, Maciel da Costa, embora demitido do Ministério do Império por Pedro I em 14 de outubro de 1824, continuou exercendo importantes funções públicas. Foi nomeado sucessivamente membro permanente do Conselho de Estado, Governador da Bahia (1825/1826), Senador (1826), Ministro dos Estrangeiros (1827) e da Fazenda (em

${ }^{3}$ Id. Ibid.: 34/40/42/44.

${ }^{4}$ CONSTITUIÇÕES DO BRASIL., 1986: 35.

Albuquerque: revista de História, Campo Grande, MS, v. 1, n. 1, p. 131-144, jan./jun. 2009 
1827, interinamente). Em 1826 foi agraciado pelo monarca com o título de Marquês de Queluz, em reconhecimento aos relevantes serviços prestados à nação. Portanto, podemos dizer que Maciel da Costa participou dos acontecimentos capitais de formação do Estado Nacional Brasileiro e fez parte, até a abdicação de Pedro I em 1831, da cúpula do sistema de poder do Primeiro Reinado.

Por essa participação de destaque na construção do Estado Nacional no Brasil, o pensamento de Maciel da Costa reveste-se de grande importância, especialmente porque contribui para a rediscussão da tese, de ampla aceitação na historiografia brasileira, de que os homens que lideraram a independência e fundaram os alicerces do Estado Nacional brasileiro eram impenitentes defensores da chamada vocação agrícola do Brasil e, por conseguinte, de uma economia agrário-exportadora, inspirada pelo livre-cambismo e lastreada indefinidamente na escravidão. Vejamos o que Maciel da Costa, um dos cardeais desse processo, pensava a respeito. Tomemos, para essa análise, a Memória escrita por ele em 1820 e publicada em 1821, cujo título completo é Memória sobre a necessidade de abolir a introdução dos escravos africanos no Brasil, sobre o modo e condições com que esta abolição se deve fazer e sobre os meios de remediar a falta de braços que ela pode ocasionar.

Como se vê pelo título acima, o tema central da Memória é o tráfico transatlântico de escravos africanos e a própria escravidão. Entretanto, ao tratar dessas questões, Severiano acabou enveredando numa discussão muito interessante sobre o papel da industrialização na formação de uma economia nacional. É sobre essa questão que versará este artigo ${ }^{5}$. Todavia, como a questão da escravidão está intimamente relacionada com o problema do desenvolvimento industrial do Brasil, será inevitável que tratemos dela também, ainda que de forma bastante sintética.

Para Maciel da Costa, assim como para o seu contemporâneo José Bonifácio, a escravidão era concebida como uma instituição incompatível com a idéia de nação. Um país - diz ele - pode ter muitos escravos, mas não contaria com cida-

\footnotetext{
${ }^{5}$ Sobre a posição de Maciel da Costa sobre o tráfico africano e escravidão no Brasil, remetemos o leitor a outro trabalho de nossa autoria: (PEREIRA, Lupercio Antonio - Para além do Pão de Açúcar. Uma interpretação histórica do livre-cambismo em Tavares Bastos - 1860/1875. São Paulo, USP, Tese de Doutorado, 2000)
} 
dãos; pode receber anualmente milhares de escravos através do tráfico, mas estaria longe de possuir uma "verdadeira população". Da mesma forma que, a rigor, não se povoa um país com braços escravos trazidos pelo tráfico externo, também a riqueza produzida pelo trabalho escravo não seria real nem sólida, mas "superficial e enganadora". Além disso, diz ele, "por efeito do maldito sistema de trabalho por escravos, a população é composta de maneira que não há uma classe que constitua verdadeiramente o que se chama povo, e este defeito deve infalivelmente influir muito no método de governo".

Assim, raciocina Maciel da Costa, forma-se, com a escravidão, uma estrutura social muito simples e potencialmente perigosa: num pólo estão o clero e a "nobreza" (isto é, os proprietários de terras e de escravos), "que é pouca" no universo da população geral; logo abaixo, está uma reduzida "classe média" representada pelos funcionários civis e militares, comerciantes, caixeiros, profissionais liberais e aqueles que vivem de rendas (proprietários de capital ou de bens imóveis), ao passo que, no pólo oposto, encontra-se o resto que forma a maioria esmagadora da população. Este "resto que deveria formar o baixo povo", diz ele, é formado "por uma enorme massa de negros escravos e de libertos, que fazem ordinariamente causa comum entre si". Com tal estratificação social, o "Estado não tem um apoio contra os desvarios da classe média, a quem dão valor, fortunas e instrução e todo o corpo social está à discrição daquela em que reside a força física", isto é, a imensa multidão formada pelos escravos e pelos libertos, estes tidos por ele como aliados naturais dos escravos. Com esse desequilíbrio, os "brancos" ficariam à mercê da massa negra, composta de "escravos bárbaros e ferozes". O autor teme a repetição, em solo brasileiro, do desastre ocorrido em São Domingos, o "primor, a jóia preciosa das Antilhas, fumando ainda com o sacrifício de vítimas humanas e inocentes", onde os "ossos de senhores legítimos" serviram de "recompensa aos vingadores de Toussainte Louverture".

Além dos inconvenientes internos já apontados, Maciel da Costa aponta ainda o perigo externo representado pela escravidão. Em seu entendimento, dada aquela composição social, haveria a possibilidade de "uma insurreição sú-

\footnotetext{
${ }^{6}$ MACIEL DA COSTA, João Severiano - "Memória sobre a necessidade de abolir a introdução dos escravos africanos no Brasil...”. In: MACIEL DA COSTA et all. - Memórias sobre a escravidão. Arquivo Nacional Fundação Petrônio Portella, Ministério da Justiça, 1988. p. 21/22.
}

Albuquerque: revista de História, Campo Grande, MS, v. 1, n. 1, p. 131-144, jan./jun. 2009 
bita [de escravos] assoprada por um inimigo estrangeiro e poderoso, estabelecido em nossas fronteiras e com um pendão de liberdade arvorado ante suas linhas". Diante de possibilidade tão horrível quão previsível, "de que nos valerão nossas forças militares?", pergunta o angustiado Maciel da Costa. Assim, conclui ele, por mais que pareça grande e próspero, um império montado a partir de tal composição social não passaria de uma "estátua de Nabucodonosor de pés de argila". Ao menor sopro transformar-se-ia rapidamente em ruínas banhadas em sangue ${ }^{7}$.

Mas, para Maciel da Costa, a inconveniência da escravidão não se restringe aos aspectos social, político e militar. Também do ponto de vista econômico, a escravidão e o tráfico africano se lhe afiguram incompatíveis com um projeto de nação moderna, porque estão indissoluvelmente associados à grande lavoura de exportação, e esta não era bem vista por ele.

Segundo Maciel da Costa, o alto grau de especialização da economia brasileira, voltada basicamente para o cultivo de uns poucos produtos de exportação (açúcar, algodão, tabaco, cacau e café), tornaria a situação do país muito precária e instável. A seu ver, o grande inconveniente é que o centro nervoso da estrutura produtiva do país estava localizado fora do país, de modo que não era possível à classe dirigente brasileira exercer qualquer controle sobre a situação. Ele entende, portanto, que, com tal estrutura produtiva, não se poderia, a rigor, admitir a existência de uma economia nacional.

Com certeza, quando falava na precariedade da economia brasileira, Maciel da Costa não pensava apenas nas oscilações normais do mercado mundial derivadas da concorrência com outros produtores ou na variação da demanda européia, ambas com efeitos imediatos e diretos sobre os preços das mercadorias exportadas pelo Brasil e que, por seu peso naquela estrutura produtiva, acabavam exercendo influência decisiva na economia do país. Com certeza, ele também levava em consideração as perturbações provocadas no comércio mundial pelos conflitos político-militares entre as potências européias. Sua Memória veio ao mundo quando a Europa ainda se recuperava da destruição provocada pelas guerras napoleônicas, cujos efeitos nos fluxos do comércio mundial são bastante conheci-

\footnotetext{
${ }^{7}$ Id., Ibid: p. 22
} 
dos. Além disso, coloca Maciel da Costa, ao insistir na introdução indefinida de braços africanos para uma expansão extensiva da lavoura de exportação, o país estaria cavando a sua própria ruína, pois poderia gerar um excesso de produção que forçaria uma baixa nos preços dos chamados gêneros coloniais. Assim, a prosperidade trazida no momento da expansão seria enganadora, porque não seria mais que a ante-sala de uma crise inevitável ${ }^{8}$.

Segundo ele, criara-se no Brasil uma situação em que o tráfico realimentava a escravidão, esta incentivava a expansão indefinida da lavoura de exportação, a qual, por sua vez, perpetuava a rotina e o atraso técnico porque "nenhum grande aperfeiçoamento se pode esperar de homens que, trabalhando para seus senhores, forçados, descontentes e sem emulação, procuram unicamente fazer quanto baste para evitar o castigo e com o menor incômodo pessoal possível. $\mathrm{O}$ corpo pode ser dominado, não a vontade, e, onde esta falta, morre a indústria" . Fecha-se, assim, um círculo vicioso cujo resultado final é a fragilidade do corpo social e o comprometimento da própria independência nacional. Como romper esse círculo?

Ora, no trecho reproduzido acima, Maciel da Costa menciona a palavra indústria, conceito que grifamos pela importância que assume em sua formulação. Deparamo-nos, assim, com o ponto nevrálgico do projeto de poder nacional concebido por Maciel da Costa. Em sua formulação, o conceito de indústria não aparece apenas como expressão de atividade produtiva em geral, como é tão comum nos autores daquela época, mas com o significado de atividade de transformação - manufatura ou maquinofatura ${ }^{10}$. Na formulação de Maciel da Costa,

\footnotetext{
${ }^{8}$ Id., Ibid: p. 24

${ }^{9}$ Id., Ibid: p. 22

${ }^{10}$ Tocqueville já nos advertiu de que as palavras possuem sua própria história, de modo que a mesma palavra pode adquirir significados diferentes conforme a época histórica. Tal é o caso do termo indústria, cujo significado ninguém hoje põe em dúvida. Embora os dicionários atuais ainda apresentem uma variedade de sentidos para a palavra, o seu uso mais corriqueiro fixou-se no sentido de atividade secundária ou de transformação da matéria prima, em contraposição às atividades primária (agricultura, pecuária, mineração e extrativismo) e terciária (serviços, etc.). Com o desenvolvimento da tecnologia e das grandes corporações industriais, a palavra passou a ser empregada também na acepção de produção uniformizada em grande escala para atender ao consumo de massas. Recentemente, foi com essa significação que o conceito de indústria passou a designar não apenas a produção em massa da área secundária tradicional (bens materiais de consumo em geral), mas também alguns
} 
não há poder ou soberania nacional sem independência industrial. Entretanto, para ele, o trabalho escravo é intrinsecamente incompatível com a atividade manufatureira ou industrial:

A força pode obrigar o escravo ao trabalho, mas a vontade não admite coação e, desgraçadamente, os meios com que a dos homens livres se estimula são inaplicáveis aos escravos. Sabemos, mesmo, por experiência, que os da África são destituídos de talento, no que são inferiores aos nossos índios, que têm provada habilidade para ofícios mecânicos. O pior de tudo é que o trabalho industrial, relegado na classe dos escravos, se aviltará aos olhos da multidão e por isso a classe livre o detestará como acontece já entre nós com o trabalho agrícola, que na opinião geral é só para escravos. (...) A história dos progressos da indústria nos tempos feudais mostra bem claramente que a condição servil dos homens lhe opõe grandes barreiras. Ora, a condição dos africanos entre nós é muito pior porque está no último grau da servidão.(...) Quem poderá preferir aos motivos morais que animam o povo industrioso de Inglaterra os vergalhos que fazem trabalhar os cativos de Argel? ${ }^{11}$

Assim, sua proposta de projeto nacional envolve:

1) medidas de controle e diminuição gradativa do tráfico africano, até sua extinção total no prazo de $20 \operatorname{anos}^{12}$;

2) combate ao que considera ociosidade da população livre e pobre ${ }^{13}$;

3) aproveitamento do trabalho indígena, para o que propõe medidas para sua "civilização"14.

ramos do setor terciário (a chamada indústria cultural representada pelos grandes meios de comunicação impressa ou eletrônica, cinema, show business, indústria fonográfica, etc.). Entretanto, quando o substantivo indústria aparece desacompanhado de adjetivo (indústria cultural, por exemplo), o seu sentido, no uso corrente, é unívoco: atividade de transformação em grande escala. O mesmo não se passava nas primeiras décadas do século XIX, quando o uso da palavra possuía ainda um sentido múltiplo ou, caso se prefira, indefinido. Exatamente essa ambigüidade de sentido tornava a palavra indústria objeto de disputa teórica entre livre-cambistas e protecionistas. Ver, a esse respeito, a interessante discussão feita por José da Silva Lisboa (Visconde de Cairu) em Observações sobre a franqueza da indústria e estabelecimento de fábricas no Brasil. Rio de Janeiro, Impressão Régia, 1810, p. $13 / 14$

${ }^{11}$ MACIEL DA COSTA, João Severiano. Op. cit. p. 23.

${ }^{12}$ Id., Ibid: p. 29

${ }^{13}$ Id., Ibid: p.37-39

${ }^{14}$ Id., Ibid: p. 35 e seg. 
4) adoção de medidas que preparem o país para, no futuro, livrar-se da chaga da escravidão. Em sua formulação, entretanto, esse futuro é remoto, pois a extinção da escravidão e principalmente dos seus efeitos nocivos sobre a sociedade "talvez custe séculos de trabalho e providências, mas nem por isso devemos desanimar porque os indivíduos morrem, não as nações, e nossos vindouros têm o direito de esperar de nós um patrimônio melhorado". Por patrimônio melhorado devemos entender não somente um país sem escravos, mas também e, sobretudo, dotado de uma população não africanizada. $\mathrm{O}$ temor à africanização do país é recorrente no texto de Maciel da Costa. Em seu projeto está clara a intenção de controlar e extinguir o tráfico em curto prazo para evitar o perigo "desse magnífico império" vir um dia a "confundir-se com a África", formando, "nessas deliciosas regiões, tão invejadas pelas outras nações, um reino do Congo"15. Entretanto, há uma contradição no pensamento de Maciel da Costa: ele oscila entre o temor da africanização e a necessidade de força de trabalho. Por isso não chega a propor a abolição imediata do tráfico de braços africanos e nem chega a defender, como Burlamaque, um projeto de fundação de uma espécie de Libéria brasileira na África para repatriação futura dos escravos alforriados ${ }^{16}$. Por outro lado, seu projeto prevê medidas de estímulo ao casamento e proteção à família escrava, como

\section{${ }^{15}$ Id., Ibid: p.27}

${ }^{16}$ BURLAMAQUE, Frederico Leopoldo César - Memória analítica do comércio de escravos e acerca dos males da escravidão doméstica. IN: Memórias sobre a Escravidão, já citada, p. 186. Burlamaque escreveu essa Memória em 1834, ocasião em que se discutia no parlamento e na imprensa as medidas legislativas para tornar realidade os compromissos assumidos no acordo com a Inglaterra que haviam redundado na lei de abolição do tráfico africano, de 7 de novembro de 1831 . O artigo segundo da lei de 1831 previa a repatriação para a África dos escravos introduzidos ilicitamente e apreendidos pelas autoridades brasileiras. Na época discutia-se como e com que meios financeiros far-se-ia essa repatriação. Um dos alvitres foi a compra, pelo governo brasileiro, de um território nas possessões portuguesas da África para instalação de uma colônia brasileira destinada a receber esses africanos apreendidos em operações de repressão ao contrabando. A idéia chegou a ser encampada pelo governo regencial, que enviou à Câmara dos Deputados, na sessão de 9 de agosto de 1934, um projeto de lei para dotação de verba destinada à compra do terreno, transporte e instalação dos negros libertos na projetada colônia brasileira na África. Entretanto, o tesouro estava em crise, a lavoura precisando de novos braços africanos, de modo que tal projeto ficou engavetado e o tráfico africano foi reiniciado com a conivência das autoridades brasileiras. O resto da história é por demais conhecido. 
forma de promover o crescimento da população doméstica de escravos. Neste sentido, pode-se aduzir que seu temor à africanização do Brasil tem um timbre cultural mais saliente que um eventual preconceito racial.

5) estímulo à imigração seletiva de europeus, canalizando-a preferencialmente para o Sul do país, região que, por sua vez, deveria "ser menos aquinhoada" na distribuição dos africanos importados no período antecedente à sua proibição total. Essa região, segundo ele, tornar-se-ia a primeira do Brasil a ser "vestida à européia", o que lhe facultaria adotar a "marcha econômica que seguem as nações cultas".

6) criar as condições para o desenvolvimento manufatureiro/industrial do Brasil. Seu escrito tem, por conseguinte, um nítido sentido de oposição aos seus contemporâneos livre-cambistas. Maciel da Costa ataca de forma contundente a principal tese defendida por estes últimos, qual seja, a de que o Brasil ainda não amadurecera para as manufaturas mais refinadas.

Nem se diga que o Brasil não deve ocupar-se tão cedo da indústria, antes deve ser ainda muito tempo puramente agrícola, com o fundamento de não estar ainda a agricultura generalizada em todo o seu imenso território e de estarmos nós ainda tão atrasados em conhecimentos, que não poderemos produzir gêneros industriais nem tão bons nem tão baratos como os estrangeiros, sendo por isso mais profícuos comprá-los do que fabricá-los. (...) Nós pensamos de outra sorte. Primeiramente, querer separar a prosperidade da agricultura da indústria, no sistema atual das nações civilizadas, é um engano palpável. Uma grande nação puramente agrícola e por conseqüência escrava de outras mais avançadas no que toca à indústria é um ente imaginário, porque não pode haver sólida grandeza sem indústria e comércio. E por toda a parte onde a agricultura não for apoiada e sustentada por uma indústria proporcionada e progressiva será sempre mesquinha e precária, e as nações que se derem exclusivamente a ela não avançarão nem em riqueza, nem em força, nem em civilização. Baste para exemplo a desgraçada Polônia, que parece ter perdido para sempre sua liberdade e independência política. ${ }^{17}$

Se a frágil Polônia agrária era o exemplo a ser evitado, a poderosa Inglaterra manufatureira e industrial era o norte a ser seguido:

Pretender, hoje, reduzir um povo inteiro ao maneio da charrua (apesar da doce influência que se atribui ao trabalho agrícola no moral dos homens) é sistema errado.

\footnotetext{
${ }^{17}$ MACIEL DA COSTA, João Severiano. Op. cit. p. 23.
} 
Ao contrário, tirar da terra o maior produto possível com o menor número de braços possível é o grande problema prático da ciência econômica. A industriosa e soberba Inglaterra pode servir-nos de modelo neste como em outros gêneros, dados também os descontos que pede sua particular situação. ${ }^{18}$

Como acabamos de ver, a Memória de Maciel da Costa indica a existência, às vésperas da Independência, de um processo de luta travado entre livre-cambistas e protecionistas. A existência dessa luta fica clara no trecho que transcrevemos a seguir:

E porque temos visto tanta gente, mesmo da classe instruída, extasiar-se com o progresso da nossa cultura atual (...) Perguntaríamos nós, agora, se esta direção da nossa agricultura para os gêneros comerciais, ilimitada, merece uma proteção absoluta e irrefletida (...) Não seria, pois, conveniente quartear essa imoderada tendência para a agricultura quase exclusiva dos gêneros de comércio externo e dirigi-la para a cultura dos cereais e mesmo dos legumes que fazem por toda parte a base da subsistência da grande maioridade do povo, segurando-a no nosso território e derramando sobre ele as somas imensas que nos levam estrangeiros? Milhões de braços ocupados com entusiasmo em lavrar a terra para alimentarem o luxo esquisito e as manufaturas da Europa, pagando ao estrangeiro o pão de que vivem e expostos a morrerem de fome, é das maiores extravagâncias que pode conceber o espírito humano. A leitura da interessante obra do professor Malthus desenganará os incrédulos na matéria (...) Merecemos desculpa ao leitor, sabendo que esta opinião contra a criação de manufaturas atualmente no Brasil é muito acreditada e por isso pareceu-nos bom insistir sobre a matéria. ${ }^{19}$

Embora não haja referência direta a seu(s) interlocutor(es), é de se supor, pela época em que escreve, que um de seus oponentes seria José da Silva Lisboa, o Visconde de Cairu ${ }^{20}$. Comparando-se as obras desses dois autores, verifica-se que o pomo da discórdia entre livre-cambistas e protecionistas é a escolha do caminho para a industrialização. Os livre-cambistas fazem a defesa daquilo que Smith chamaria de caminho natural, ao passo que os protecionistas acreditam na possibilidade de se tomar atalhos na história para se chegar mais rapidamente à indústria. Este é o caso de Maciel da Costa, para quem o caminho natural que

\footnotetext{
${ }^{18}$ Id., Ibid: p. 24

${ }^{19}$ Id., Ibid: p. 30/56 (grifos nossos).

${ }^{20}$ CAIRU, Visconde. Estudos do bem comum e Economia Política. Rio de Janeiro, IPEA/INPES, 1975.
}

Albuquerque: revista de História, Campo Grande, MS, v. 1, n. 1, p. 131-144, jan./jun. 2009141 
vai gradualmente da agricultura à indústria é longo demais, conforme se vê na transcrição abaixo:

Pretender, pois, que uma nação principiante se ocupe ao princípio da agricultura exclusivamente e que se não divirta para a indústria senão quando o último canto do seu território se achar cultivado e a cultura levada à maior perfeição é correr após de uma quimera, é supor causa aquilo que não é senão efeito, é ignorar a marcha natural e prosperidade das nações modernas. ${ }^{21}$

Entretanto, se é cético quanto à possibilidade de cooperação mundial, Maciel da Costa mostra-se grande otimista quando se trata de calcular as possibilidades de passagem de uma nação agrícola para o estágio industrial. Vejamos, no trecho seguinte, como essa concepção se manifesta de forma cristalina em seu pensamento.

Acresce que esse inconveniente de comprarem os consumidores nacionais mercadorias menos boas e menos baratas das nossas fábricas não pode ser senão passageiro porque o governo, que tem sempre ante os olhos o termômetro econômico, vem em socorro da indústria nacional pelos muitos meios que tem à sua disposição. (...) E se o governo empregar os meios possíveis para adiantar os conhecimentos auxiliares, de maneira que possamos exceder ou igualar as outras nações ou ao menos marchar à pouca distância delas, não desaparecerão esses sacrifícios, que tanta bulha fazem na cabeça dos exagerados amigos dos consumidores? Seria curioso ver demonstrar quais são esses embaraços invencíveis que temos nós para empreender sem esperança de sucesso: estabelecimentos industriais. Não vemos porque motivo não poderemos fabricar excelentes panos de lã, algodão, linho e seda; que profundos conhecimentos nos faltem para extrair, preparar e fundir o ferro das riquíssimas minas que temos; para fundar cordoarias dos muitos e variados gêneros naturais de que abundamos; para fabricar chapéus, lonas, brins; para preparar breu, alcatrão e aproveitar infinitas gomas e resinas e, enfim, outros muitos produtos de consumo geral e de fácil manipulação. Mas quando nos faltem meios e mestres, por que os não mandaremos vir dos estrangeiros $?^{22}$

Em vários aspectos, a formulação de Maciel da Costa é muito semelhante à de G. F. List, mas diferencia-se bastante deste no que diz respeito às condições históricas julgadas necessárias à industrialização. Nesta questão, a formulação de Maciel

\footnotetext{
${ }^{21}$ Id., Ibid: p. 24

${ }^{22}$ Id., Ibid: p. 25/26 (grifos nossos).
} 
da Costa é muito distinta da de List. O voluntarismo de List não era ilimitado, pois ele entendia que não haveria mágica capaz de fazer qualquer país, independente de suas condições históricas, saltar do estágio pré-industrial para o industrial. Como deixa claro, embora o protecionismo lhe parecesse eficaz para alavancar a industrialização da Alemanha ou dos Estados Unidos, essa fórmula não se aplicaria automaticamente a qualquer outro país. List deixa claro também que o protecionismo deveria ser adotado por tempo limitado, em torno de 20 anos.

Assim, vemos que Maciel da Costa considera extremamente difícil a superação da escravidão, mas relativamente fácil a industrialização. Ele entende, corretamente, que a passagem para o trabalho livre era uma tarefa pontilhada de imensas dificuldades. Reconhece na escravidão uma relação social cujas implicações abrangiam todas as instâncias da vida em sociedade, inclusive o aspecto cultural. Não é sem motivo, portanto, que deixe de estipular prazo para a abolição da escravidão e calcule em séculos o tempo necessário para que os vestígios culturais da escravidão desaparecessem por completo na sociedade brasileira. Neste sentido, embora afirme o contrário, entende corretamente que a escravidão e a grande lavoura eram a forma possível de produção da vida "civilizada" no Brasil oitocentista. Na linguagem da época de Maciel da Costa, sociedade civilizada significava uma sociedade hierarquizada e produtora de excedentes para manter o pouco de vida de estilo ocidental, obviamente que confinada aos extratos superiores da sociedade. Apesar de, na parte inicial de sua Memória, fazer enfáticas declamações em contrário, na seqüência Maciel da Costa acaba pactuando com a escravidão, de forma que sua condenação revela-se apenas retórica. $\mathrm{Ou}$ melhor, sua condenação pode ser sincera, mas é feita com base em um princípio abstrato que, afinal, tem de se conformar com as imposições do mundo real e com as exigências da produção mercantil que, no Brasil daquela quadra histórica, ainda dependia do trabalho escravo ${ }^{23}$.

No que diz respeito à indústria, por outro lado, Maciel da Costa subestima as dificuldades porque não a concebe como uma relação social. Como diria Marx,

\footnotetext{
${ }^{23}$ Sobre as dificuldades, contradições e vacilações no processo de transição do trabalho escravo para o trabalho livre no Brasil, ver outro trabalho de nossa autoria (PEREIRA, Lupercio Antonio Limites históricos do pensamento abolicionista. Uma contribuição ao estudo do gradualismo adotado na abolição da escravidão no Brasil. Assis, UNESP, Dissertação de Mestrado, 1987).
}

Albuquerque: revista de História, Campo Grande, MS, v. 1, n. 1, p. 131-144, jan./jun. 2009 
ele entendeu indústria como uma reunião de coisas para fabricar coisas e não como relação social. Talvez resida aí a grande fragilidade e a ineficácia política de seu discurso industrialista. Entretanto, em que pese essa limitação, a Memória de Maciel da Costa sugere que, no mínimo, vejamos com maiores cautelas o velho axioma historiográfico de que o processo de independência foi conduzido por uma elite política e intelectual deslumbrada com o liberalismo econômico. Se a presença de livre-cambistas convictos não pode ser negada naquele processo, o escrito de Maciel da Costa nos mostra, pelo menos, que não havia, entre os chamados "próceres da independência", a unanimidade imaginada por muitos historiadores quanto à conveniência da continuidade da economia escravista e agrário-exportadora. 